\title{
PROFESSIONAL DEVELOPMENT AS A MOTIVATOR OF GENERATION Y
}

\author{
Krystyna Kmiotek ${ }^{1}$
}

\begin{abstract}
Along with Generation Y entering the market place, the human resources specialists have selected significant generation differences. The generations vary in values, expectations, approach to work, supervisors, and organization. These differences are very important for human resources management improvement as well as the motivation system in a company. The existing survey shows that Generation Y greatly appreciates the possibilities of professional development at work and it is important inducement for young employees.

The aim of the article is to identify the approach of Polish Generation Y to their professional development and confirm that companies have to offer suitable conditions for professional development to attract and maintain the biggest talents. Based on the questionnaire survey conducted among generation $\mathrm{Y}$ employees, we attempt to answer the following questions: "is the possibility of professional development the most important motivator?" "Could the lack of the company support for professional development be the reason for giving up the job?" "How does Generation Y take care of their own professional development?" The research shows that the possibility of professional development is not the most important motivation factor for Polish generation Y; this is because they value family, personal relations, and time for their passions or relaxation more. In fact, these factors are more valuable for Generation Y than money and work.

Furthermore, for young employees the lack of support in professional development by the organization is an important aspect that could cause them to leave the organization. Despite good preparation for work, generation Y employees still pursue further education, while working, in order to enhance their professional development. Human resource management practice in Polish companies should consider these conclusions under the scope of motivation system and talent management.
\end{abstract}

JEL Classification Numbers: M5, J53, DOI: http://dx.doi.org/10.12955/cbup.v2.459

Keywords: Generation Y, motivation, human resources, management, professional development

\section{Introduction}

For many years, Generation Y has caught the attention of both theorists and practitioners who attempt to answer the questions of "what is the new generation of employees like?" and "what is important for them?" The answers to these questions are of substantial importance from the point of view of human resources management in a company. This need is justified by demand for information from three perspectives: (1) improvement of HR practices with particular consideration of motivation system, appropriate to managers' expectations; (2) gaining of relevant knowledge in order to effectively manage organizational diversity with respect to generations; and (3) re-thinking of the strategy and recruitment techniques in order to keep Generation Y employees engaged. Thus, this Generation must be understood in order to attract them to the company and keep them. This understanding will also allow companies to create work environment favoring this group of employees (Hutchinson et al., 2012).

The aim of the article is to identify the approach of Generation Y to their professional development, which is a very important inducement. Implementing the assumed aim, we present the results of questionnaire survey conducted among 532 employees who were, selected as representatives of Generation Y-namely the persons who were born after 1981, and are employed in six companies located at the area of Lower Silesia, Poland. Based on the results obtained, we attempt to answer the following questions: "is the possibility of professional development the most important motivator?", "could the lack of the company support for professional development be the reason for giving up the job?” and "how do Generation Y take care about their own professional development?”

\footnotetext{
${ }^{1}$ Krystyna Kmiotek, Rzeszow University of Technology, Poland, krystyna.kmiotek@prz.rzeszow.pl
} 


\section{The characteristics of Generation Y employees}

The most important HR priorities for the future of organizations include talent management, learning and development, as well as engagement (European HR Best Practice Report, 2011). The improvement of these practices requires profound recognition of both organizational conditions and the employees' needs and expectations in this respect. Special attention should be paid to Generation Y employees whose values, approach to work, and supervision differ significantly from those of older generations simultaneously functioning in the workplace. Spotted differences between generations may lead to conflict escalation, preventing the organization from achieving success. The authors suggested that understanding these generational differences may be a tool that managers can use to create more employee productivity, innovation, and corporate citizenship (Wey Smola et al., 2002).

The division into particular generations in the literature is conventional and unequivocal, though differences between suggested generation gaps are minor (up to 5 years). The authors agreed that currently four generations are present at the workplace (Glass, 2007):

- Generation S or the "Silent Ones" or the "Traditionalists" (born between 1925 and 1945),

- Generation B or the "Baby Boomers" (born between 1946 and 1964),

- Generation X (born between 1965 and 1980),

- Generation Y, often referred to as "Gen Y," or the "Millennials" or "Echo Boomers" (born between 1981 and 1994).

The practitioners' interest in Generation Y, originating from the necessity to improve HR procedures and their adjustment to employees' expectations, resulted in a number of reports in which the characteristics of Generation Y employees, differentiating them from older generations, were identified. The following characteristics of Generation Y are mentioned (Plink, 2009; Generation Y, 2008; Shaffer, 2008):

- Technologically savvy — used to continuous information access, overload, and feedback.

- Used to social networking, possess different perception of privacy, and are aware of the risks of social networking.

- Good leadership, display of strengths, and personal development are necessary for Gen Y.

- If Gen Y are not well-managed, not excited by their job or not developed, they will be dissatisfied and demotivated; they will not put up with it for a long time and they will resign.

- Gen Y learns differently to former cohorts; they prefer to learn from their peers and through coaching and mentoring. Most of all, they look for "fun" and multi-sensory experiences.

- They expect flexible working hours; they need appraisal and continuous feedback; they like to work in teams or collaboratively; they are task-oriented; they expect employers to be good corporate citizens; they would like the company to provide time for volunteer and community involvement; they value their relationship with their direct supervisor the most.

The authors also pointed out, in particular, that Gen Y is fairly unique in their adoption and use of digital media; it demonstrates very positive view on cultural diversity and social issues in the part driven by their higher levels of education. Moreover, they are strongly orientated with their family and social groups, and they experience a longer period of adolescence than previous generations with the need for "instant gratification" becoming one of the behavioral outcomes (Leask et al., 2013). As employees, Generation Y tends to want an intellectual challenge, need to succeed, strive to make a difference, and seek employers who will further enhance their professional development (Hurst \& Good, 2009). Looking for the best motivator for Generation $Y$ in the area of financial incentive is not one of the best approaches, this is because cohort contribution to society, good parenting, and a fulfilled and balanced lifestyle appear to be more motivating and meaningful for them. 
Bearing in mind the fact that Generation Y grew up in the conditions when knowledge and skills are decisive for the possibility of getting an attractive job, Gen Y's approach to professional development seems to be an interesting issue. On one hand, the level of knowledge and skills of one person constitutes a socially accepted value; on the other hand, it constitutes an element of a motivation system, which should comprise both the possibilities and needs of a company, and the aspirations and expectations of employees. We assume that professional development, as a process of improving and increasing capabilities of staff through access to education and training opportunities in the workplace (through outside organization or through watching others perform the job), is considered an important element of human resource development. Development implies the growth or realization of a person's ability and potential through the provision of learning and educational experience (Armstrong, 2006).

\section{Professional development as a motivator}

The presented research was conducted, in the period from March to June 2013, in six companies located in the area of Lower Silesia, in the form of an electronic questionnaire. The respondents constituted 532 employees, the representatives of Generation Y, or the persons born after 1980; 73\% and $27 \%$ of whom were women and men, respectively. Among the respondents, $58 \%$ and $42 \%$ were single and were married, respectively. With respect to education, the respondents' structure was as follows: $3 \%$ had vocational education; 32\% had secondary education; and $65 \%$ had higher education. Taking into consideration the experience of unemployment, 53\% of respondents had remained unemployed for some time, while $47 \%$ had never had this experience.

The conditions of knowledge-based economy make specialized knowledge and skills, held by an employee, a determining factor for one's earning capacity; thus, they are decisive of the situation on the job market. It may be assumed that for well-educated younger generation, the possibilities of professional development will find its place in their system of values. The place of professional development among other values of the surveyed employees of generation $\mathrm{Y}$ is presented in Figure 1.

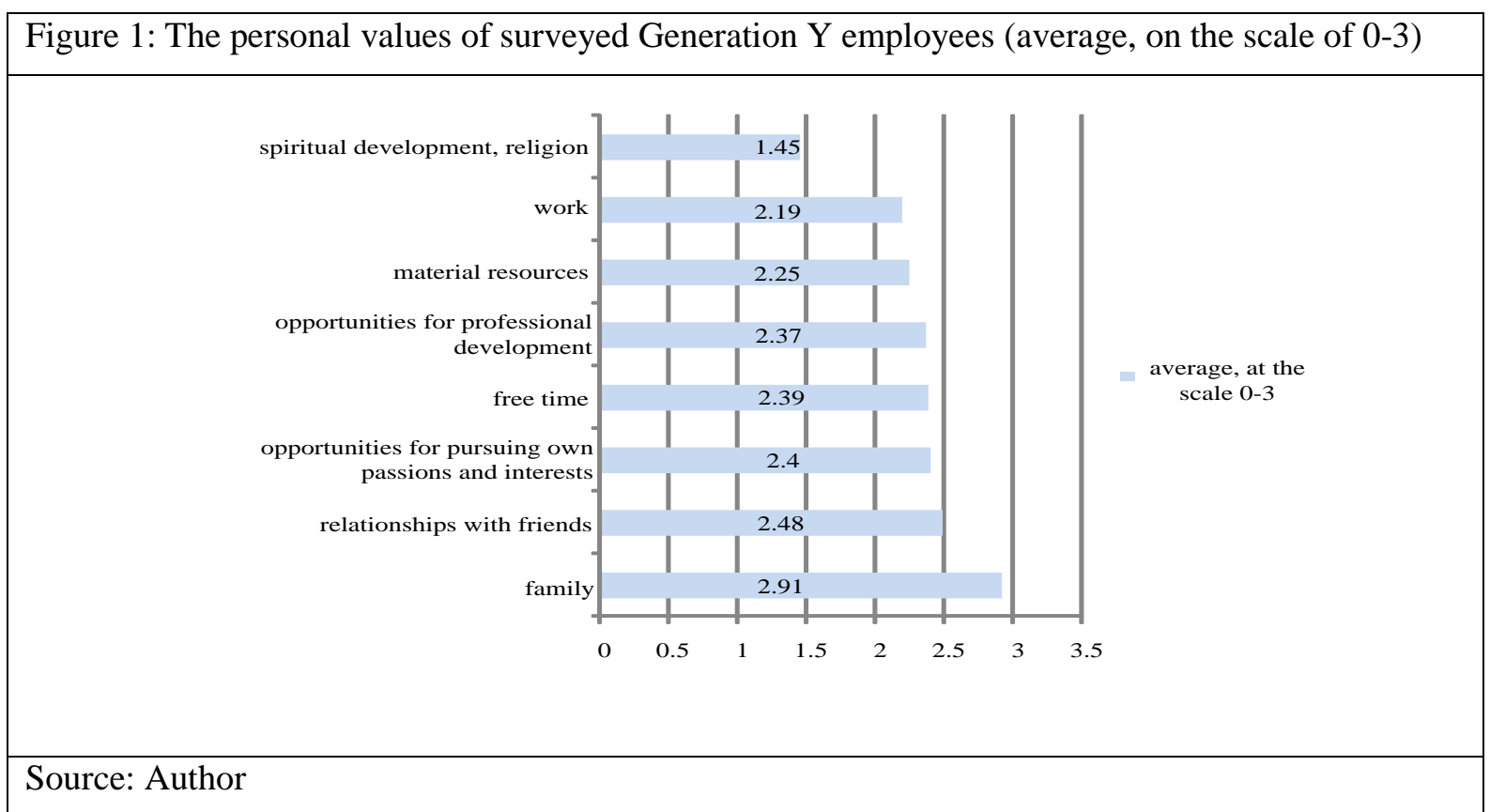

The survey results indicate that respondents value family the most (the average rating of 2.91). Highly cherished values also include relations with friends (2.48), the possibility to pursue passion, interests (2.4), and leisure time (2.39). The possibility of professional development was ranked further down the list. As it turns out, relationships with family and friends are most important for younger employees, followed by their own needs (passions and leisure time) then by professional development. 
It is interesting to see that the aspects of material resources and work are of less importance for the respondents.

To determine factors influencing the respondents, the relationship between the respondents' answers, sex, education, marital status, and unemployed experience were further analyzed. The occurrence of relations was determined on the basis of Person's independence test $\left(\chi^{2}\right)$. Adopting the significance level $(\alpha)$ of 0.05 , test probability ( $p$ ) for particular hypotheses was calculated. If $p>\alpha$, then the gathered empirical material gives no grounds for hypothesis rejection; however, if $p<\alpha$, then on the basis of gathered empirical material, the hypothesis is rejected. On the basis of obtained results, it may be found that statistically there occurred a significant dependence between the assessment of the importance of professional development possibilities, as a life value, with sex and marital status. In the conducted survey, women more often demonstrated that professional development is important and men more often assessed professional development as very important. Neither women nor men assessed this aspect as unimportant. This suggested that professional development is preceded by other values in women's hierarchy of values; for men, it will constitute one of the most important values more frequently. Married respondents more often assessed professional development as important, while single respondents more often demonstrated that professional development is a very important value in their lives. This is related to the difference in life priorities and the stage of professional career; respondents with family tend to focus on other aspects of life, while those without a family are more focused on the development of their professional skills.

The possibility of professional development is an important aspect of work, which has an impact on employee motivation. For young employees, it is an important motivational aspect due to a desire to growth at early stages of their career. Gaining the first-hand experience at work may reveal their shortcomings, compared to older colleagues, as well as create an awareness of deficiencies in knowledge and skills. This in itself may push young people to take actions oriented at professional development. The respondents' responses regarding important aspects of work are shown in Figure 2.

Figure 2: The importance of selected aspects of work in the opinion of surveyed employees of Generation Y (the average, on the scale of 0-3)

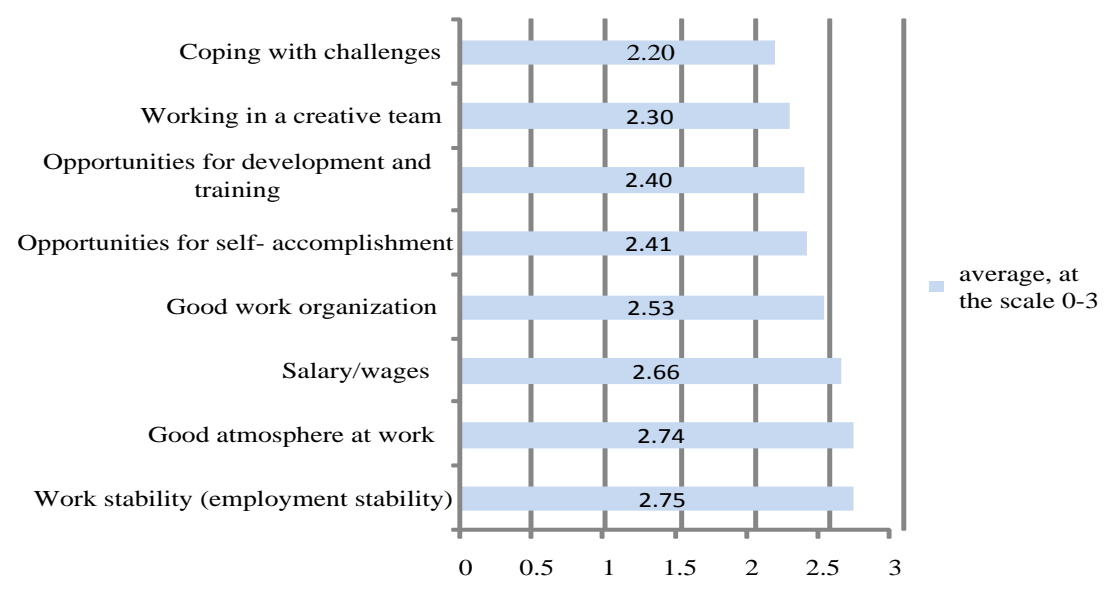

Source: Author

From the survey results shown, it can be pointed out that for Generation Y employees, the following aspects are most important regarding work: employment security (2.75) and good working atmosphere (2.74). The following aspects are also important: wages (2.66), work organization (2.53), the possibilities of self-fulfilment (2.41), and development (2.40). Statistically significant dependencies 
were not determined between the assessment of possibilities of development and trainings and sex, education, marital status, and unemployment experience.

Thus, it may be stated that for surveyed respondents, the following values are more important than development possibilities: job security, good relations, and wages, which provide the possibility of the attaining cherished values.

\section{The strive for professional development of Generation Y employees}

Upon completing education and taking up one's first job, an employee may have some idea about his or her skills, knowledge and the impression whether this is sufficient to achieve professional success. Along with gaining experience and dealing with reality, these views may change. The respondents were asked in the questionnaire how they assess their professional background from the current perspective. $16 \%$ of respondents assessed it as "very well," while $53 \%$ assessed as "well." Attention should also be paid to respondents' high self-esteem regarding the recognition of situation in the job market. $90 \%$ of surveyed employees know the employer's requirements toward its employees; $87 \%$ have good recognition of work and wages conditions offered by the employers. Moreover, these employees believe that, as a generation, they are more motivated to care for their professional development (78\%), compared to older generations. Moreover, it also turns out that Generation Y employees are not contempt with just having a solid professional background, while being employed, many of them declare that they also strive for their own professional development (89\%).

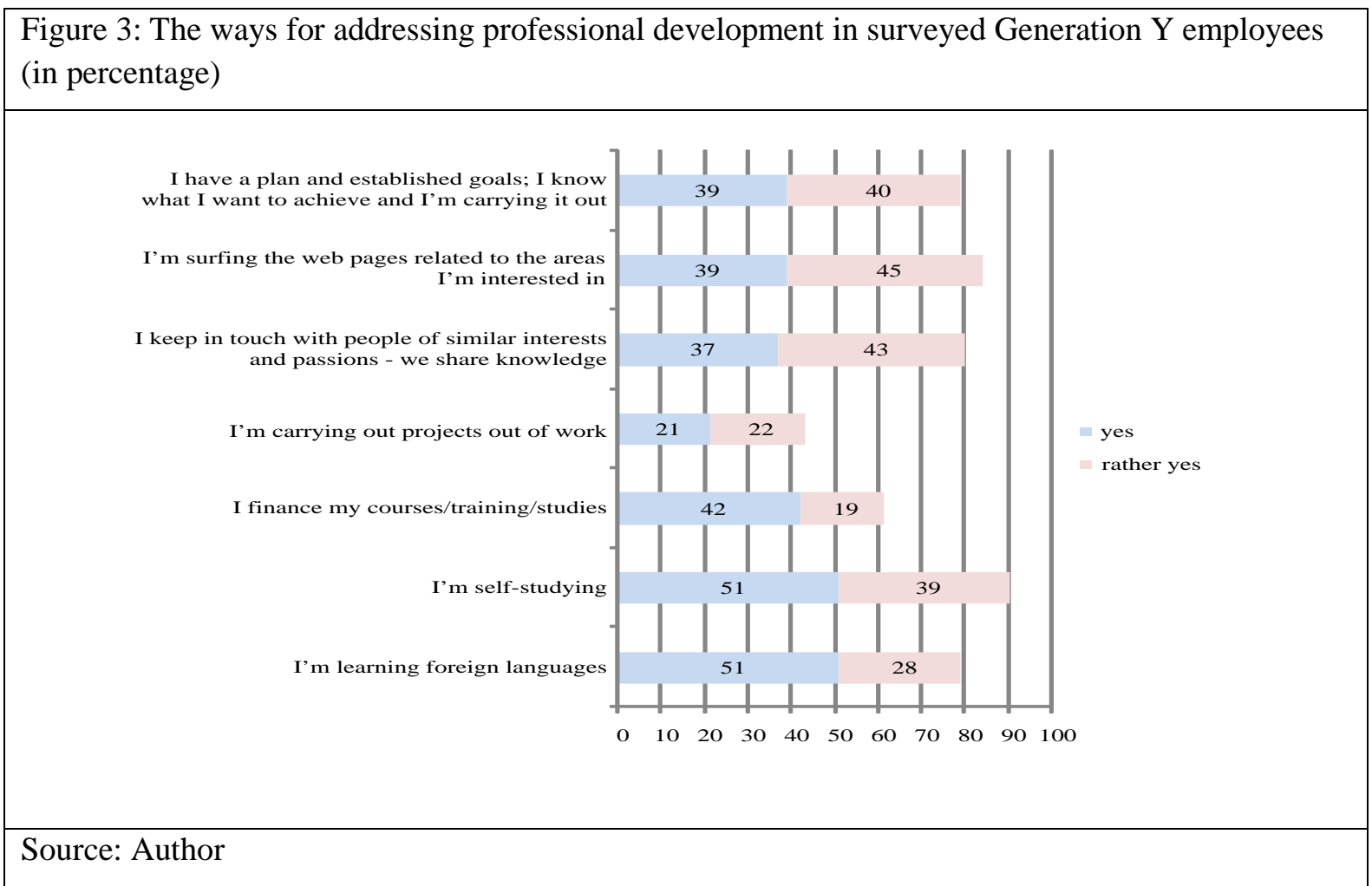

The responses to the question on how the respondents view their professional development are presented in Figure 3. The results obtained lead to a statement that striving for professional development by questioned employees involve various actions. When asked if they supplement knowledge independently, 51\% of respondents answered "yes" and 39\% answered "rather yes" (meaning "somewhat yes"); when asked if they also surf the web to learn more about related issues of their interest, 39\% of respondents answered "yes" and 45\% answered "rather yes"; when asked if they keep in touch with persons with similar interests in order to share knowledge, 37\% said "yes" and 43\% said "rather yes"; and when asked if they learn foreign languages, 51\% said "yes" and 28\% said 
"rather yes." Moreover, a significant percentage of respondents were asked if they have their own plan in professional life and if they aim at achieving it; 39\% answered "yes" and $40 \%$ answered "rather yes." A significant percentage of respondents also invest in their development (42\% answered "yes" and 19\% answered "rather yes."

The studies of reference literature mentioned the fact that Gen Y employees are much oriented toward relation building. Thus, there arises a question of "to what extent these employees expect support in the scope of their own professional development from their superiors and colleagues?” The results obtained show that the respondents expect the establishment of work conditions to be motivating for development (55\% "yes" and 36\% "rather yes"). They also expect their superiors to provide support (66\% "yes” and 30\% "rather yes”). The surveyed employees' expectations toward their colleagues are slightly different; $31 \%$ of respondents definitely expect inspirations for development and $49 \%$ of respondents rather do not expect it.

Thus, it may be said that the surveyed Generation Y employees addressed their professional development by gaining knowledge independently, financing their education, using the internet resources, building relations, and enabling them to share related knowledge. Furthermore, their professional development is well thought out and planned. They search for support in development from their superiors; though to a lesser extent, they expect inspiration in this respect from their colleagues.

\section{The lack of support in the scope of professional development as a reason for resignation from work by Generation Y employees}

One of the distinctive characteristics of Generation $\mathrm{Y}$ is in their different perception of loyalty compared to previous generations (Plink, 2009). For previous generations, it is possible to determine the subject of loyalty (organisation, profession, and themselves), while it is difficult to indicate such a characteristic among Generation Y employees. Therefore, the identification of these characteristics as the decisive aspects of work, which are attractive, important and valued by the young generation, is a challenge for employers. Is the possibility of professional development a decisive factor? The respondents' opinions on professional development are presented at the Figure 4.

Figure 4: The opinions of surveyed employees of Generation Y on professional development (in percentage)

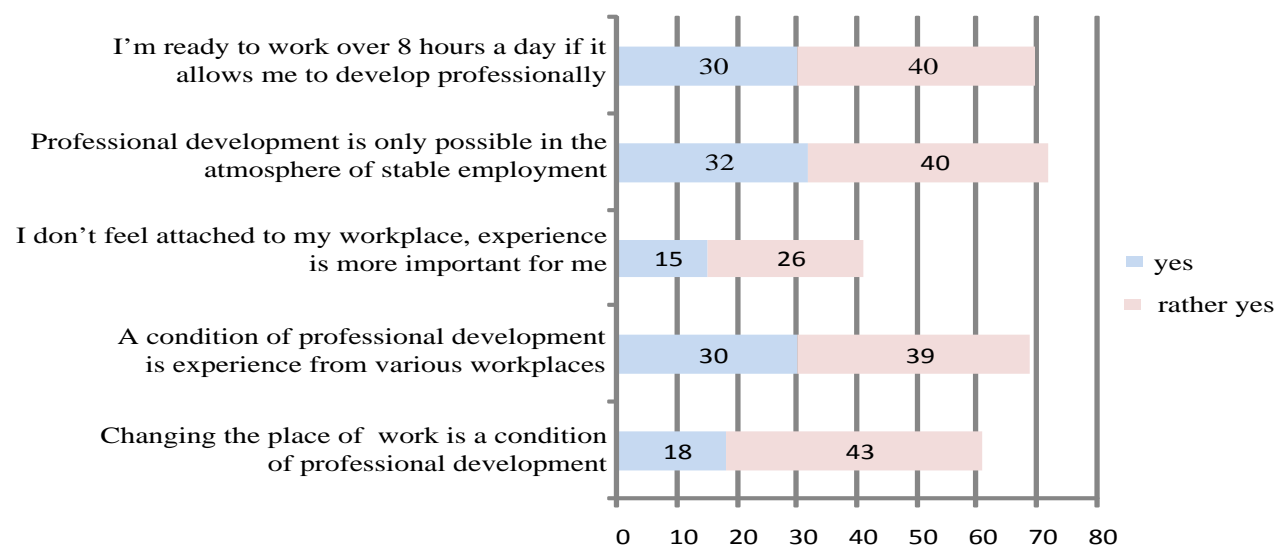

Source: Author 
The most popular response from the surveyed employees on the professional development suggested a need for stable employment (32\% of respondents answered "yes" and $40 \%$ "rather yes"). A slightly smaller percentage of respondents is willing to devote more time to work than required by legal regulations if this favors their professional development (30\% answered "yes" and 40\% answered "rather yes"). It turns out that the smallest percentage expressed little organizational attachment due to the priority in one's own professional development (15\% answered "yes" and 26\% answered "rather yes"), and not many more respondents definitely express the opinion that the condition for professional development is the change of workplace. On the other hand, the respondents appreciate the significance of experiences from various workplaces for one's own professional development (30\% answered "yes" and 39\% answered "rather yes").

Therefore, it may be concluded that the Generation Y respondents, with regard to their professional development, value the atmosphere of employment security; they are rather willing to devote more time to work; they appreciate the possibility to gain experience from various workplaces; and only a minor percentage of respondents value their own professional development more than their attachment to the company which they work.

The surveyed Generation Y employees were asked a question about potential reasons for resignation from work, which included the lack of support in the scope of professional development on the part of the company (Figure 5).

Among questioned employees, the lack of support on the part of the employer with respect to professional development, as the reason for resignation from work, was definitely supported by $28 \%$ (this is the least percentage from all proposed reasons for resignation), and $42 \%$ responded that they would rather resign. In addition, better job opportunity elsewhere and salary dissatisfaction are also popular among Gen Y employees’ reasons for resignation from work.

This survey allows us to state that there is a statistically significant dependence between the willingness to resign from work due to the lack of support in professional development and education and the experience of unemployment. It turns out that persons with higher education are more often ready to leave work, whereas those with vocational education and secondary education are much more cautious in holding on to their jobs.

Figure 5: Potential reasons from resignation from work by surveyed employees of Generation Y (in percentage)

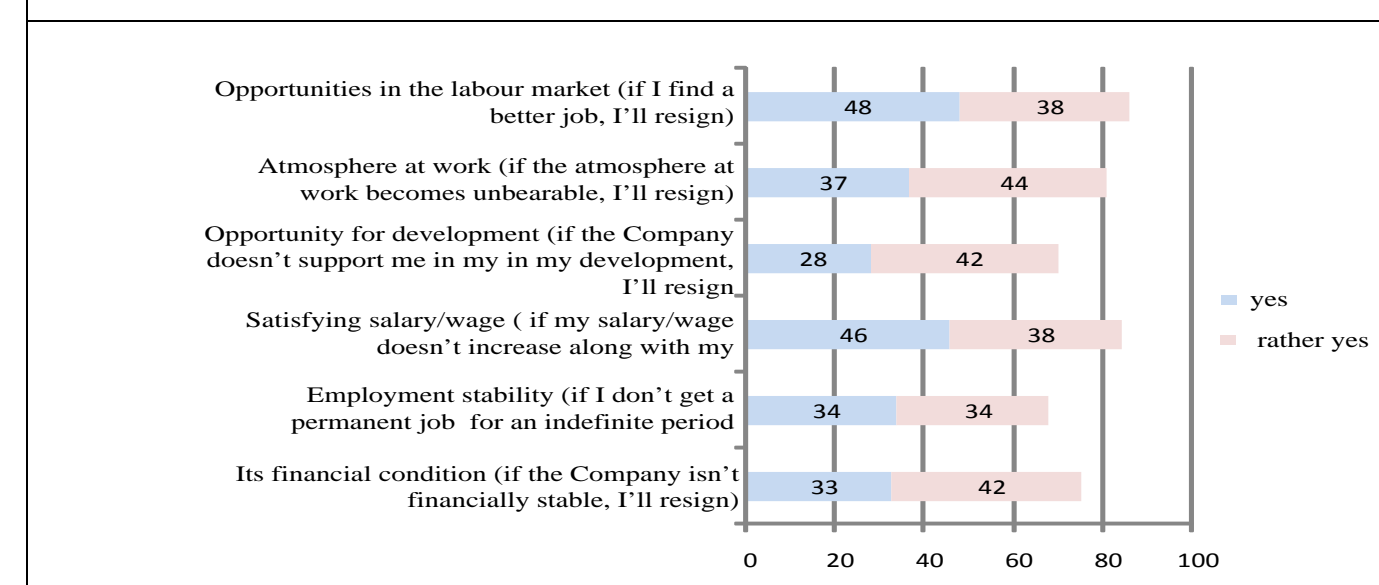

Source: Author 


\section{Conclusion}

In formulating answers to the research questions in this article, it can declared that the possibility of professional development is not the most important motivating factor for Generation Y employees. In fact, they are mainly family-oriented; they value relations and time devoted to pursuing their passions or recreation. However, professional development still finds its place on the list of values cherished by the young generation; it is valued even more than financial resources and work itself. In Polish conditions, the differences in the approach to professional development with respect to gender are noticeable; men rank professional development as one of the most important value in life, and the same may be said about single persons. Considering professional development as a motivating factor and the element of motivation system in a company, it was found that this is an important motivational factor for Generation Y employees, but is less valued than employment security, atmosphere at work, and work organization or remuneration. These aspects, especially employment security, favor professional development in the respondents' opinion.

Secondly, although Generation Y employees perceive themselves as well prepared for professional life, they assess themselves to be driven than older generations in this respect; they do not stop their education and, while working, they strive for their professional development. This attribute is demonstrated in various ways such as by financing traditional forms of education, learning independently (e.g. using of the internet), and building relations for knowledge sharing.

Thirdly, the survey conducted demonstrates that the lack of support in professional development by the organization is a decisive aspect, which could cause the Generation Y employees to leave the organization. Other reasons influencing these employees to resign from work may include a more attractive job offer, a higher remuneration, bad atmosphere at work, etc. Thus, these aspects should not be neglected as a potential reason for resignation from work.

Despite some limitation of the survey presented, namely the selection of survey sample made of the employees of six companies with a defined business activity profile, which may limit the representativeness, the comparison to other surveys indicates some similarities. The survey presented demonstrated that the surveyed group of Gen Y Polish employees have share common characteristics with their peers from other countries. The common characteristics may include the orientation toward workplace relations; the similar conclusions were made in the survey of employees in the financial sector in London, New York, Sydney, Frankfurt, and Tokyo. These surveys also demonstrated a different approach of Generation Y to frequent change of the workplace, so called "job-hopping." It seems that the surveyed group of Polish employees is closer, in this respect, to their peers from Frankfurt and Tokyo, who showed less willingness to change the workplace (Beyond the baby boomers, 2007).

Moreover, a statement that the possibility of development is an important motivating factor, which cannot be omitted in a company motivation system, was also confirmed. However, from the practical point of view, the structure of the motivation system for younger generation should include, in the first place, the conditions that favor the maintenance of work-life balance. This implies an increase in remuneration combined with the increase in employee competencies, as well as actions aimed at creating favorable work atmosphere.

\section{Acknowledgement}

The research has been financed within a grant by National Science Centre Poland, decision No. 2011/03/B/HS4/05695. 


\section{References}

Armstrong, M. (2006). Strategic Human Resource Management. A Guide to Action. London and Philadelphia: Kogan Page.

Beyond the baby boomers: the rise of Generation Y. Opportunities and challenges for the funds management industry (2007). KPMG Investment Management and Funds.

Business Dictionary (n.d.). Retrieved December 22, 2013 from http://www.businessdictionary.com

European HR Best Practice Report - Full Report 2011 (2011). A CRF Institute Benchmark Study on Top Employers in Europe. The CRF Institute.

Glass, A. (2007). Understanding generational differences for competitive success. Industrial \& Commercial Training, 39(2).

Hurst, J. L., \& Good L. K. (2009). Generation Y and Carter choice. The impact of retail career perceptions, expectations and entitlement perceptions. Career Development International, 14(6), 570-593.

Hutchinson, D., Brown, J., \& Longworth, K. (2012). Attracting and maintaining the Y Generation in nursing: a literature review. Journal of Nursing Management, 20, 444-450.

Leask, A., Fyall, A., \& Barron, P. (2013). Generation Y: An Agenda for Future Visitor Attraction Survey. International Journal of Tourism Survey. John Wiley \& Sons, Ltd.

Plink, D. (2009). Retention $Y$ What is the key to retention of Generation Y? Whitepaper Generation Y. CRF Institute.

Shaffer, J. (2008). Gen Y Talent: How to Attract and Retain the Young and the Restless. Saba White Paper.

Talentsmoothie (2008). Generation Y: What they want from work. A summary report of the "Tell it how it is" Survey 2008. Retrieved from http://talentsmoothie.com/sbd/wp-content/uploads/2012/09/Copy-of-GenYtellithowitisA4Final.pdf.

Wey Smola, K., \& Sutton, Ch. D. (2002). Generational differences: revisiting generational work values for the new millennium. Journal of Organizational Behavior, 23, 363-382. 